\title{
Illustrate mud-fluid conduits and their variety using resistivity image profiling method in Southwest Taiwan
}

\author{
Nan-Ting Yen ${ }^{1}$, Ting-Li Lin ${ }^{1, *}$, Ling-Rong Liao ${ }^{1}$, Ping-Yu Chang ${ }^{2}$, and Himanshu Mittal ${ }^{1}$ \\ ${ }^{I}$ Department of Earth Science, National Cheng Kung University, Tainan City, Taiwan \\ ${ }^{2}$ Department of Earth Science, National Central University, Taoyuan City, Taiwan
}

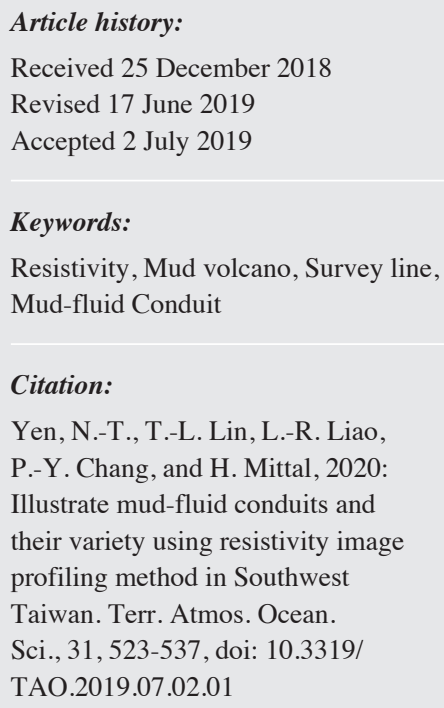

\begin{abstract}
We conducted 2D resistivity survey along nine survey lines and inverted them to 3D model by combining 2D data in the Gunshuiping mud volcano in order to understand: (1) the relationship between the resistivity image and the mud-fluid distribution, and (2) the influences of earthquakes and typhoon on mud volcanoes. The three long survey lines passed through the four craters, out of which one was active during the survey period; and the six short networked lines surrounded the crater $2(\mathrm{C} 2)$. The results reveal that a vertical structure is present beneath crater 3 (C3), whom we interpret a conduit transporting the mud-fluid onto the near surface. Also, an area with low resistivity (less than $4 \mathrm{ohm}-\mathrm{m}$ ) is found at a certain depth suggesting to be the mud-fluid chamber. The high resistivity (more than $4 \mathrm{ohm}-\mathrm{m}$ ) distribution is found near the surface, and we suggest that the mud volcano craters communicate with each other by the 3D model. Moreover, after the Meinong earthquake of 6 February 2016, the resistivity rose obviously within about $10 \mathrm{~m}$ under the surface; while the resistivity of the mud-fluid conduits declined. We also found that after the earthquake, the original active crater (C3) had stopped and was replaced by another crater $(\mathrm{C} 1)$. We inferred that when the earthquake happened, the gases escaped to the surroundings and caused the gas content of the shallow surface to increase. Besides, as the original crater collapsed, the gases needed another crack to release, which made another crater re-activate. The data also shows that after the typhoon, the resistivity of mud-fluid conduits rose with the active crater changed again from $\mathrm{C} 1$ to $\mathrm{C} 4$.
\end{abstract}

\section{INTRODUCTION}

The two-dimensional (2D) resistivity survey is widely used in the environmental, engineering, hydrological, archeological, and mineral exploration applications (Irawan et al. 2013; Loke et al. 2013; Crawford 2018). In some cases, dense 2D sections are combined to resolve a three-dimensional (3D) resistivity structure (Bernstone et al. 1997; Dahlin and Loke 1997), as 3D resistivity presentation is more appropriate for illustrating detailed subsurface structures in a heterogeneous environment (Dahlin et al. 2002).

A mud volcano is a geological landscape which has a complicated mechanism. High-pressure gas, water and thick mudstone are necessary to form mud volcano. Mud volcanoes can be found around the globe; for example, Trinidad, United States, Azerbaijan, Pakistan, China, Java, and Italy

\footnotetext{
* Corresponding author

E-mail: ljegay1111@gmail.com
}

(Martinotti et al. 2015). Mud volcanoes originate as a consequence of fast depositional processes (Martinotti et al. 2015) occurring in a wide variety of tectonic environments, such as passive continental margins (Hedberg 1980), continental interiors (Fertl and Timko 1970), transform (Higgins and Saunders 1974) or convergent plate boundaries (Stride et al. 1982), and submarine slopes (Martinotti et al. 2015).

Considering the effectiveness of electrical resistivity method in studying subsurface structures, it has been used rigorously in studying the variation of mud volcanos in different part of world. Chang et al. (2011) conducted 2D and 3D looped resistivity surveys in the Wushanting Natural Landscape Preservation Area (WNLPA) of Southern Taiwan in order to understand the relationships of the mud-fluid conduits in the mud volcano system. The relationship between resistivity and gas hydrate concentration in the subsurface of mud volcanoes through Transient Electromagnetic technique 
and resistivity method was studied by Vignesh et al. (2013). They considered three volcanos in Andaman region of India after great Sumatra earthquake of 2004. Chitea (2016) performed vertical electrical soundings and electrical resistivity tomography in Romania in the area of the Homorod mud volcano occurrence, aiming to evaluate the extruded material electrical signature and the possibility of a non-invasive evaluation of the near surface mud chambers, as well as to track the feeder channel. Salamov et al. (2017) applied resistivity method on one profile with the use of four-electrode symmetrical installation to investigate subsurface structure of Dashgil mud volcano in Azerbaijan.

Earthquakes and typhoons have proven to affect resistivity in mud volcanos. The effect of earthquakes on resistivity variations has been studied previously by many researchers (Yang et al. 2002; Chang et al. 2010). In this study, we surveyed $2 \mathrm{D}$ resistivity profiles to generate $3 \mathrm{D}$ resistivity model in order to investigate the mud-fluid conduits of the Gunshuiping mud volcano system in Kaohsiung City, Taiwan. We also observed the resistivity variations induced by the seismic waves of the Meinong Earthquake of 6 February 2016 (Wu et al. 2016) and heavy rainfall caused by typhoon Megi and Meranti in September 2016 respectively.

\section{SITE DESCRIPTION}

In southwestern Taiwan, abundant mud volcanoes have erupted on land and offshore owing to the intensely compressed tectonic environment and to the thick mud deposits (Shih 1967; Huang et al. 1992; Liu et al. 1997). Milkov (2000) indicated that there is a close relationship between mud volcanoes and gas hydrate. Gas in mud volcanoes is believed to be closely related to organic matters decomposed in the mudstone formation (Chang et al. 2010), and dissociated gas hydrate (Yeh 2003). The Gunshuiping mud volcano, located in Southwest of Taiwan, is an active geological system. Yeh (2003) suggested that the origin of the gas and fluid in the Gunshuiping mud volcano are related to gas hydrate. Most of the on land mud volcanoes at southwestern Taiwan are related to the geological structures and are distributed along the axis of the Gutingkeng anticline and the Chishan fault (Wang et al. 1988). The study area, the Gunshuiping mud volcano, is also sited at southwestern Taiwan, which is located in Yanchao District, Kaohsiung City (Fig. 1). The mud volcano is situated at the thick Gutingkeng mudstone area, which is located near to the Chekualin fault and Gutingkeng anticline axis. The distances from the Gunshuiping mud volcano to the Chishan fault and Gutingkeng anticline axis are of about $5-6$ and $7-8 \mathrm{~km}$, respectively. The rock layers of this area from top to down are mainly divided into alluvium deposits (layers of sand and mud), terrace deposits (gravel and sandstone, extending up to $100 \mathrm{~m}$ ), Chi-Ting Formation (thick-bedded to fine-grained sandstone and the dark gray mudstone in upper layer and dark gray mudstone interbedded with sandstone and limestone in the lower layer extending to $700 \mathrm{~m}$ ) and

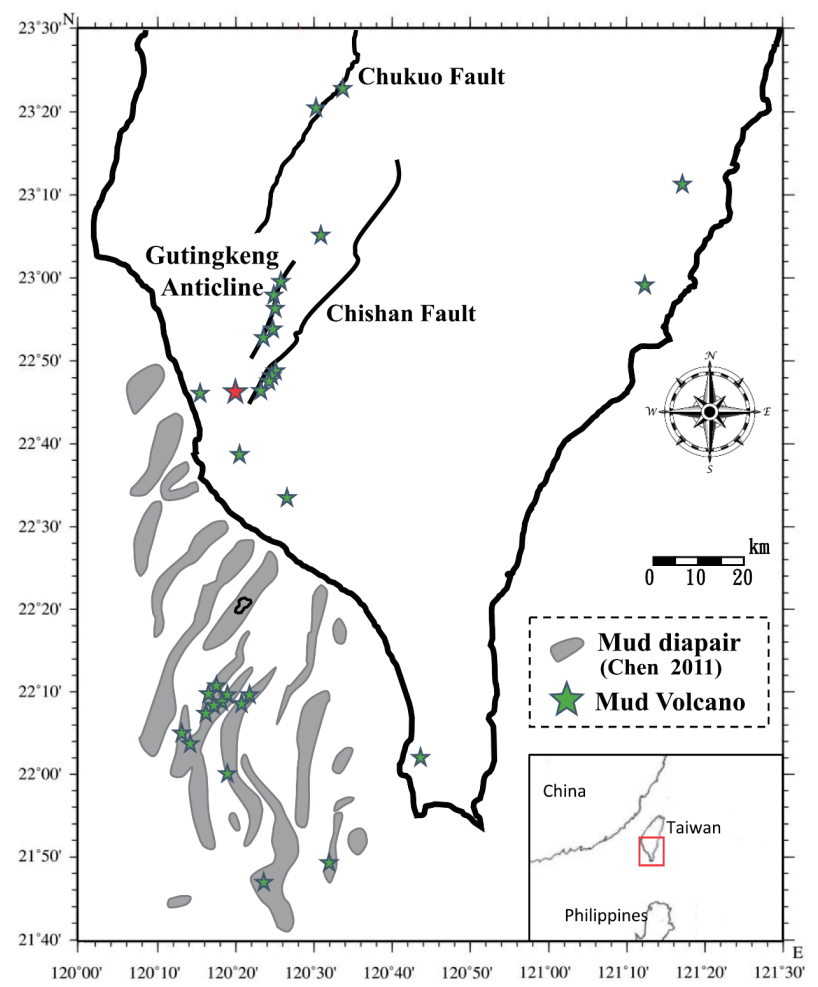

Fig. 1. The mud volcanoes distribution in southwest Taiwan, and the red star is our research location Gunshuiping mud volcano. 
Gutingkeng Formation (composed of dark gray argillite, and some parts interbedded with Amherst stone extending till $1700 \mathrm{~m}$ ). From the chemical analysis, it is found that the mud from the eruption of Gunshuiping Mud Volcano is mainly produced from Gutingkeng Formation.

At the Gunshuiping mud volcano, the gas composition contains methane $96.4 \%$, carbon dioxide $2.2 \%$, nitrogen less than $2 \%$, and the others (Chao and You 2003). The fluid is composed of the gas hydrate dissociating water, ancient marine deposits water, and groundwater.

There are four noticeable craters in the Gunshuiping mud volcano spread in $175-\mathrm{m} \times 90-\mathrm{m}$ area and are indicated as craters C1, C2, C3, and C4 in this study (Fig. 2). During the preliminary work of this study, crater $\mathrm{C} 1$ has stopped erupting and ceased, and the crater $\mathrm{C} 3$ is more active than the others. C2 has erupted before we surveyed, and it looks like a small mod pond. Then after the Meinong Earthquake in February 2016, C3 has stopped erupting and C1 has been reactive, and the similar situation also happened after Typhoon Meranti and Typhoon Megi in September 2016. After the typhoons struck, $\mathrm{C} 1$ has stopped erupting once again and the new crater $\mathrm{C} 4$ has been formed around $20 \mathrm{~m}$ away from $\mathrm{C} 1$. Afterward, there was no change in the activity of the craters and the general landform until the end of this study.

\section{SURVEY CONFIGURATIONS}

In this study, we measured nine resistivity survey lines (Fig. 3a) using the layout of the Wenner array to image the $3 \mathrm{D}$ resistivity profile. Wenner configuration of resistivity profiling uses two current electrodes $(\mathrm{C} 1$ and $\mathrm{C} 2)$ and two potential electrodes $(\mathrm{P} 1$ and $\mathrm{P} 2)$ arranged in a line $\mathrm{C}_{1} \mathrm{P}_{1} \mathrm{P}_{2} \mathrm{C}_{2}$. The electrode spacing $\mathrm{C}_{1} \mathrm{P}_{1}=\mathrm{P}_{1} \mathrm{P}_{2}=\mathrm{P}_{2} \mathrm{C}_{2}$ is equidistant so that $\mathrm{C}_{1} \mathrm{C}_{2}$ is three times of $\mathrm{P}_{1} \mathrm{P}_{2}$ spacing and depth of investigation is approximately equal to $\mathrm{P}_{1} \mathrm{P}_{2}$ spacing. The electrode number, as well as electrode locations used during survey,

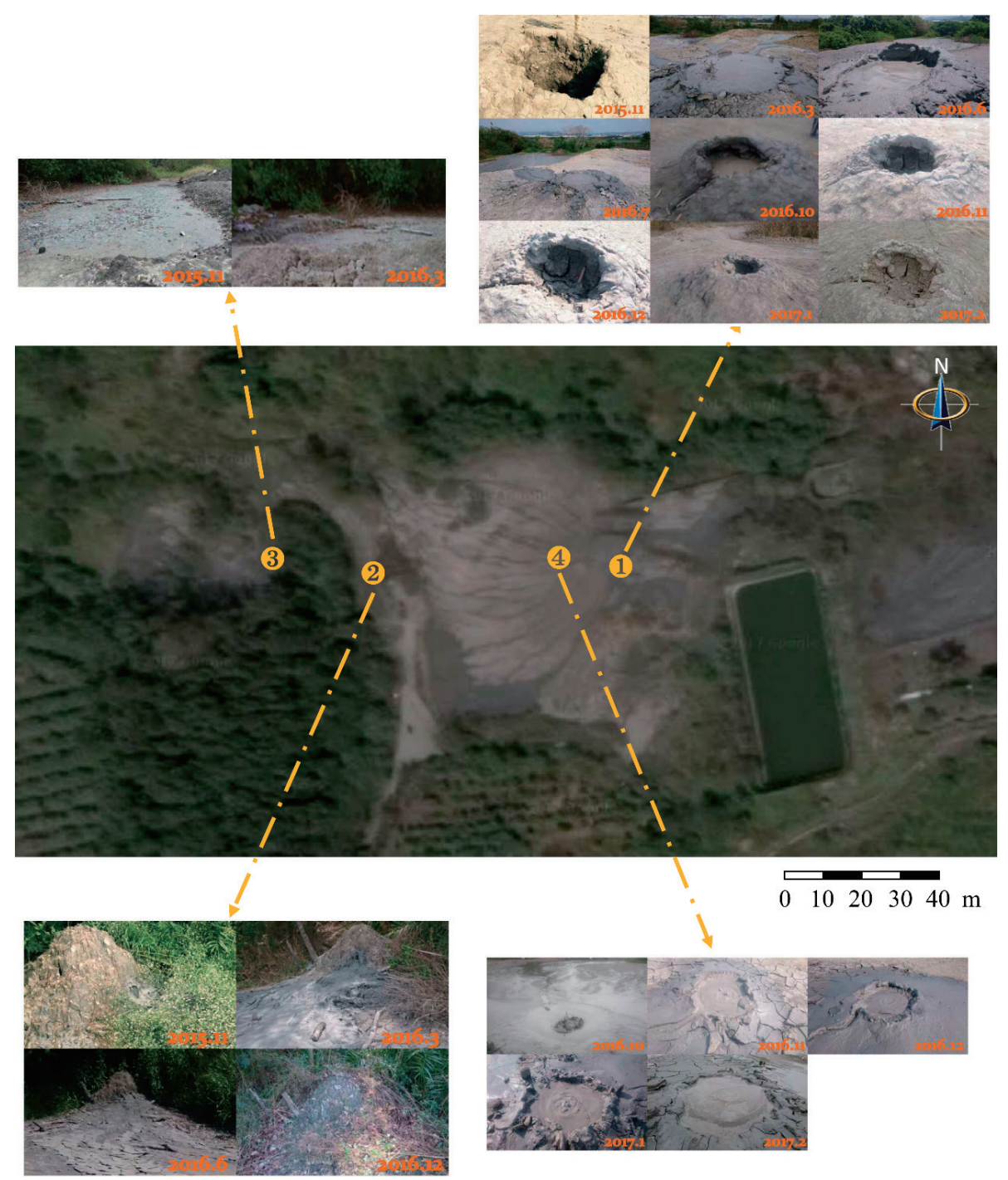

Fig. 2. Pictures showing the location of Gunshuiping mud volcano and craters 1, 2, 3, and 4 labelled as C1, C2, C3, and C4. 

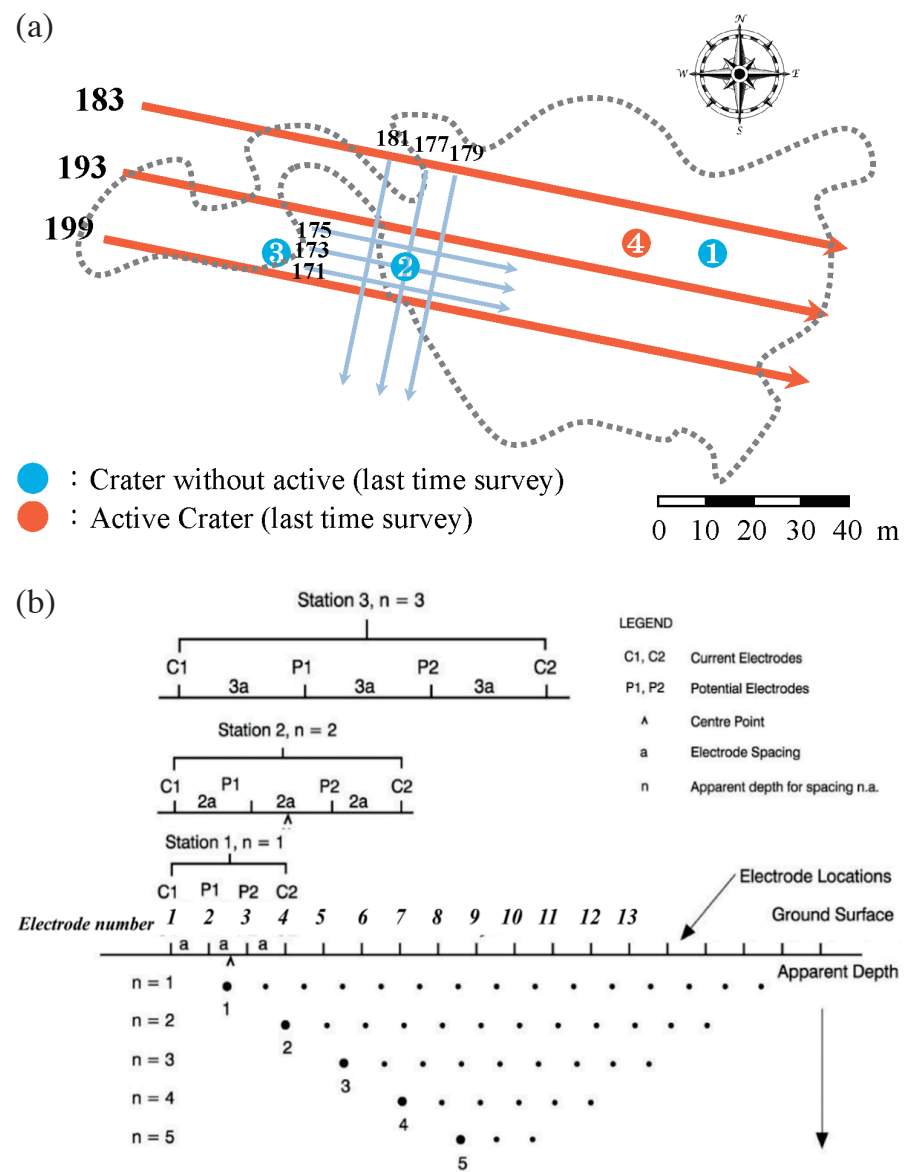

Fig. 3. Map of Gunshuiping mud volcano and configurations of 2D survey lines. The three long survey lines are named as 183, 193, and 199, respectively. Six other short lines surround C2 in West-East and North-South directions (a). (b) shows the electrode configuration used during survey.

are illustrated in Fig. 3b. Lines 183, 193, and 199 are the long lines with a length of $155 \mathrm{~m}$. Lines $171,173,175,177,179$, and 181 are the $45-\mathrm{m}$ survey lines surrounding the crater $\mathrm{C} 2$. Lines 171, 173, and 175 are in the east-west direction, and lines 177,179 , and 181 are in the north-south direction. We then combined these $2 \mathrm{D}$ resistivity results to invert the $3 \mathrm{D}$ models. RIP method is used to measure the apparent resistivity of the formation by an actual field setting instrument, and then obtain a resistivity profile through the inverse calculation process of the data. The instrument used in this study is the McOHM PROFILER 2140F geoelectric surveyor manufactured by OYO Corporation of Japan. A forward modeling subroutine is used to calculate the apparent resistivity values, and a non-linear least-squares optimization technique is used for the inversion routine (Loke and Barker 1996). The program supports both the finite-difference and finiteelement forward modeling techniques. This study uses the Res2dinv program developed by AGI in the United States, which uses a two-dimensional profile inverse program (Loke and Barker 1996) to invert the measured data. The advantage of this method is that it can be clearly distinguished under conditions of relatively smooth formation changes, such as changes in fines in the soil, or gradual changes in physical and chemical properties in the soil, since the study area is mudstone. The main and observed content is the change in resistivity for each period, so the data obtained is suitable for using this inversion algorithm. One of the models is inverted by lines 183,193 , and 199 and the other model is combined from lines 171, 173, 175, 177, 179, and 181, which surround the crater $\mathrm{C} 2$. After the Meinong earthquake, we re-conducted the resistivity survey along Lines 183, 193, and 199; and looking upon the results related to resistivity change, we finally selected the Line 193 to conduct several times of resistivity survey to observe the effects of the earthquake and the typhoon to the in-situ resistivity.

\section{RESULTS AND DISCUSSION}

We conducted the resistivity survey in Gunshuiping mud volcano in order to delineate the conduits beneath and find the possible relation between conduits and vertical structures. The interpretation is presented in two parts (along the long survey lines and small survey lines) as described in the survey configurations. 


\subsection{Long Survey Lines 183, 193, and 199}

Figures $4 \mathrm{a}-\mathrm{c}$ show the results of the $2 \mathrm{D}$ resistivity survey along survey lines 183, 193, and 199, respectively. There is the low resistivity (less than $4 \mathrm{ohm}-\mathrm{m}$ ) area clearly evident beneath $\mathrm{C} 3$ in the form of vertical structure (Fig. 4a, pink arrow). As seen from Fig. 4b, an area with low resistivity is found at depths between 3 and $14 \mathrm{~m}$, whom we interpret as a mud chamber (purple square) acting as temporary mud storage during mud eruption. Towards the top right of the profile images (Figs. $4 \mathrm{a}-\mathrm{c}$ ) and between $\mathrm{C} 1$ and $\mathrm{C} 2$ (about $0-5 \mathrm{~m}$ ), a horizontal conduit is present connecting the two craters. Beneath the craters $\mathrm{C} 2$ and $\mathrm{C} 3$, a tilted conduit is observed at a depth of $5-12 \mathrm{~m}$ (black arrow in Fig. 4c), which connects the two craters.

The results showed that the vertical structure (purple square in Fig. 4c) below C3 was the main mud-fluid conduit in Gunshuiping area, and the three craters were communicating with one another through the mud-fluid conduits (black arrow).

The 2D resistivity profiles obtained along three long survey lines $(183,193$, and 199) are combined and inverted to produce the 3D model (Fig. 5). Looking at Fig. 5, the same kind of results are obtained as that of $2 \mathrm{D}$ profile images (Fig. 4c). The resistivity value $1-8 \mathrm{ohm}-\mathrm{m}$ is divided equally in different isopleths, and so the values of isopleth are $1.1,1.3,1.5,1.7,1.9,2.2,2.5,2.8,3.2,3.7,4.2,4.8,5.4$, $6.2,7.0$, and $8.0 \mathrm{ohm}-\mathrm{m}$. The main mud-fluid conduit in the form of vertical structure can be seen clearly (pink arrow in Fig. 5) below $\mathrm{C} 3$. The tilted conduit joining the main conduit below $\mathrm{C} 3$ and horizontal conduit between $\mathrm{C} 2$ and $\mathrm{C} 1$ is represented by another pink arrow. It is clearly visible that tilted conduit is located between $\mathrm{C} 3$ and $\mathrm{C} 2$ located at the depth $5-12 \mathrm{~m}$. The result of the 3D model is similar to the 2D profile images.

We combined the three long survey lines to invert 3D model and made the $\mathrm{Z}$ direction resistivity cross-sections at different depths (Fig. 6). At near surface (about 0 - 5 m), C2 and $\mathrm{C} 1$ are connected with each other, and at a depth about $5-12 \mathrm{~m}$, the tilted conduit (purple square) located beneath $\mathrm{C} 2$ and $\mathrm{C} 3$ was connecting with the conduit between $\mathrm{C} 2$ and $\mathrm{C} 1$. The result showed that the three craters were attached with one another, which is in agreement with results obtained from Fig. 5.

\subsection{Short Survey Lines 171, 173, 175, 177, 179, and 181}

Lines 171, 173, 175, 177, 179, and 181 are the short survey lines surrounding the $\mathrm{C} 2$ in West-East and NorthSouth directions. Figures $7 \mathrm{a}-\mathrm{c}$ show the results of $2 \mathrm{D}$ resistivity profile along lines 175,173 , and 171 respectively (from west to east). A low resistivity area near the surface is marked by the purple box in Fig. 7b, and this low resistivity area is conduit joining craters $\mathrm{C} 2$ and $\mathrm{C} 1$. These results are the same as that of along long survey line 193.

On the other hand, Figs. 8a - c show the results obtained along lines 179, 177, and 181, respectively (from north to south), and the results displayed that the conduit was focused in the west (purple square beneath $\mathrm{C} 2$ in Fig. 8c) and it diffused in the east (purple square marked from the distribution along survey line 179 in Fig. 8a). We considered that the $\mathrm{C} 2$ was the transition of the mud-fluid conduit. We also found that the high resistivity piled up at near surface and surrounding the $\mathrm{C} 2$ (Fig. 9). The phenomenon is similar as observed by Chang et al. (2010) and suggested that the gas erupt within mud-fluid and do not erupt directly into the atmosphere.

\subsection{Resistivity Change Before and After an Earthquake Along Long Survey Lines}

After Meinong Earthquake, we found that $\mathrm{C} 3$ had stopped functioning and was replaced by $\mathrm{C} 1$ in the area. When the earthquake occurs, the seismic waves shake the mud and the accumulated gas is hard to be saved in the mud so that it escapes to the surroundings and causes the gas content of the shallow surface to increase. The gas content of the mud decreases at the same time. Moreover, as evolving over time, the mud volcano system affected by earthquake will gradually recover by itself. Temporal variations in gas composition during and after an earthquake are studied and discussed previously by many researchers (Sugisaki and Sugiura 1986; Walia et al. 2013), where gas acts like an earthquake precursor.

In order to understand the influence of earthquake for Gunshuiping mud volcano, we re-conducted the resistivity survey. The results revealed that resistivity rose obviously within about $10 \mathrm{~m}$ below the surface, while the resistivity of the mud horizontal conduits decayed (Figs. 10a - c). The same kind of observation is made along all three long survey lines.

\subsection{Resistivity Changes of Line 193 During Different Periods}

Figures $10 \mathrm{~b}$ and $11 \mathrm{a}-\mathrm{d}$ show the 2D profile images of resistivity change along line 193 in this study during different time intervals. Figure 10b shows the resistivity change along long survey line 193 before and after the Meinong Earthquake. As described earlier, resistivity is found to increase within $10 \mathrm{~m}$ below surface especially at $40-60 \mathrm{~m}$ from the origin, and then a few months later after Meinong earthquake the resistivity declines as shown in Figs. 11a - b. The Meinong earthquake happened on 6 February 2016 and resistivity started decaying in following months (Fig. 11a showing change from March 2016 to June 2016). The released gas during an earthquake caused a decrease in water content and consequently increase in resistivity (Chang et 
al. 2010). Figure 11c shows the change of the resistivity before and after the typhoon. Three different typhoons namely Nepartak, Meranti, and Megi were felt during the observation period. Apart from the increase in resistivity of the mud channel, a new crater is found to form around $90-95 \mathrm{~m}$ along X-axis. Finally, the Fig. 11d shows the change of the resistivity during the dry season.

\subsection{Comparison of Each Survey Period Data with Pre-Earthquake Data Along Line 193}

By comparing the results from each survey period with a pre-earthquake period (November 2015), we can understand the impact of the earthquake event on the study area and the time required to return to the initial situation. The results showed that in the beginning, the resistivity of the shallow surface increased and of the mud beneath it decreased.
By June, the resistivity gap had been drastically reduced. However, the significant resistivity difference in deeper areas may be affected by the groundwater level (Fig. 12a). By July 2016, almost no obvious difference was observed between the two data, owing to the fact that this earthquake affected the shallow surface of the study area for about five to six months before it returned to the pre-earthquake state (Fig. 12b). It is observed from Fig. 12c that the resistivity of the bushes area is lower than the initial value and this value increases beneath the bushes. Following the previous observation that the influence of the earthquake has ended in July 2016, these changes may be attributed to the torrential rain brought by the typhoon. In addition, the formation of crater C4 (about 90 - $95 \mathrm{~m}$ on the surface) and at the same location in Fig. 10b is marked by an increase in resistivity. Therefore, the formation of $\mathrm{C} 4$ may be caused by the earthquake cracks; and when $\mathrm{C} 1$ stops working, a new eruption position
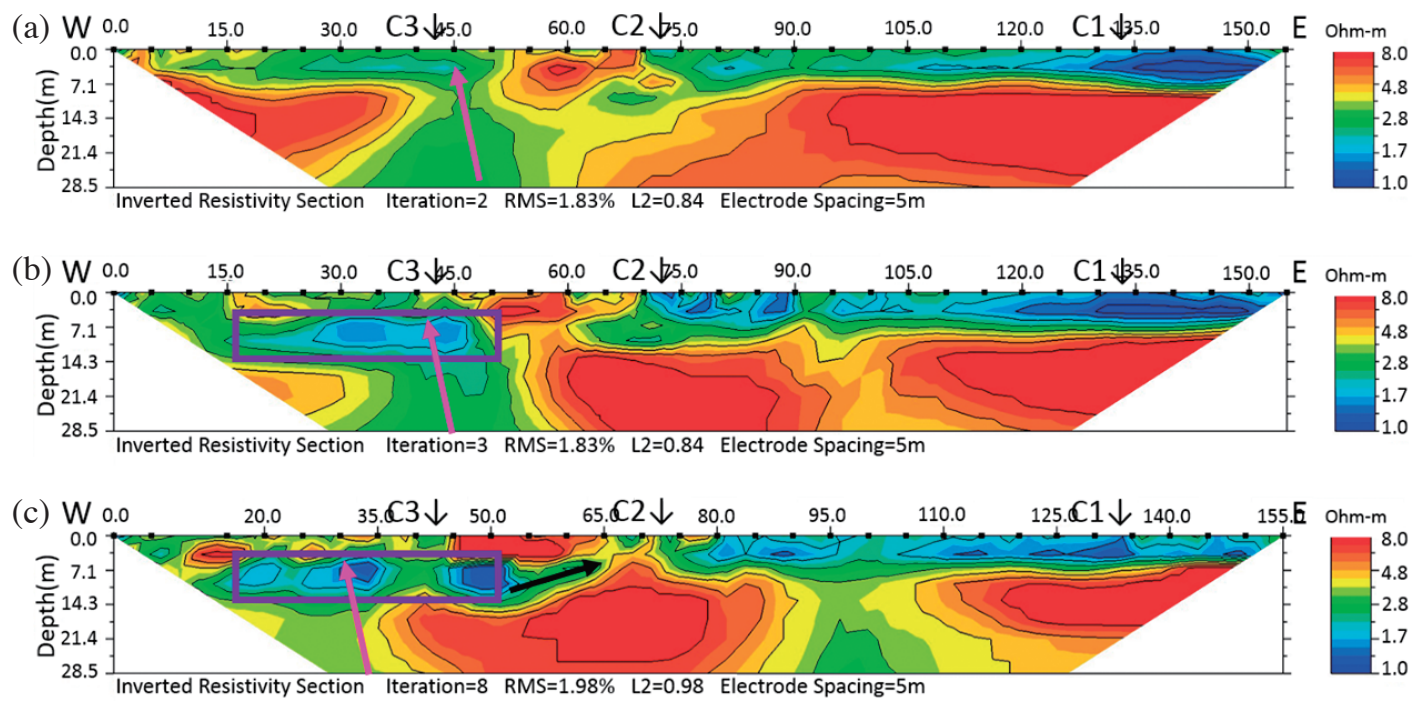

Fig. 4. 2D profile section of Line 183 (a), 193 (b), and 199 (c). C1, C2, and C3 were the three craters. The pink arrow marks the site of the main mud-fluid conduit, and the purple square is the location of mud-fluid chamber. The black arrow points out the branch connecting $\mathrm{C} 3$ with $\mathrm{C} 2$ and $\mathrm{C} 1$.

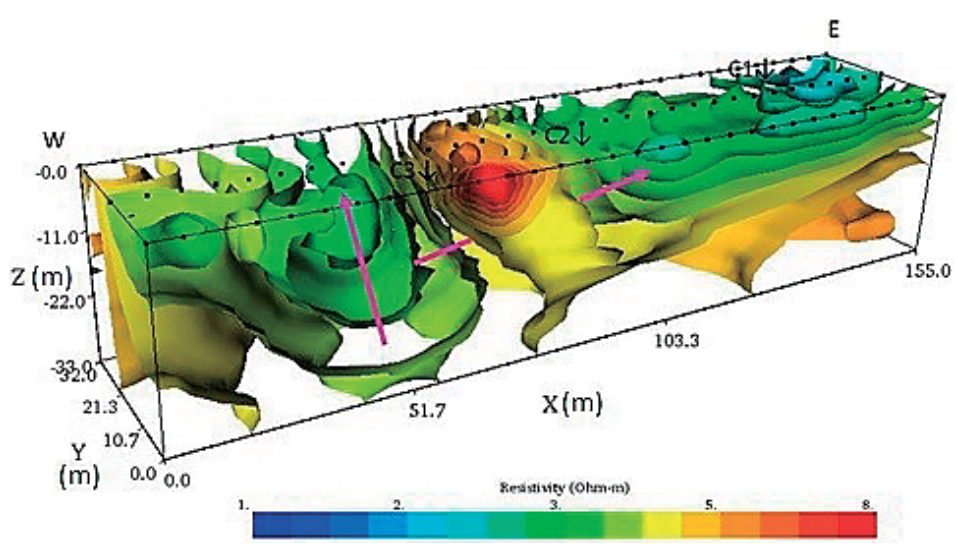

Fig. 5. The 3D model made created by combining and inverting the results from Lines 183, 193, and 199. The pink arrows point out the site of mudfluid conduit. The another pink arrow points the site of branch which is connecting with the parallel conduit. 

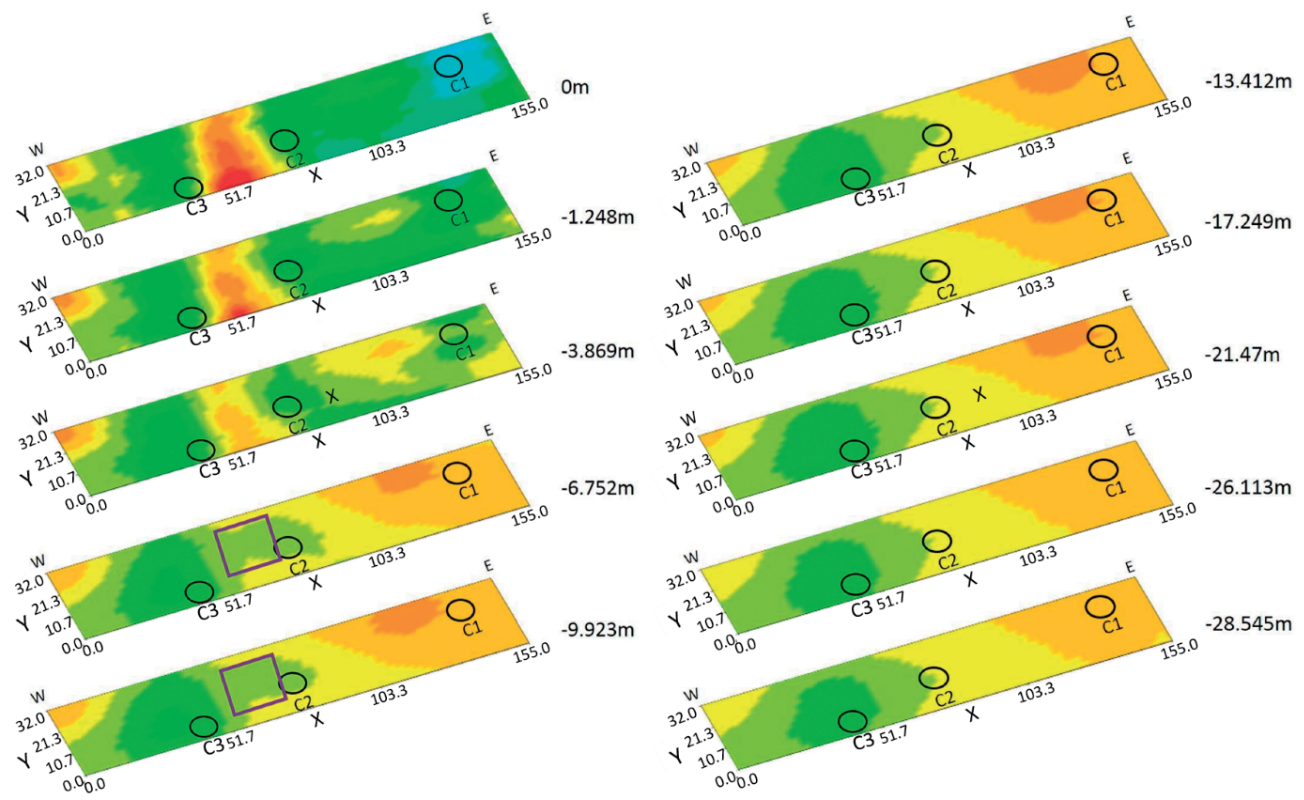

Resistivity (Ohm-m)

$\begin{array}{llll}1 . & 2 . & 3 . & 5 .\end{array}$

Fig. 6. The cross sections of 3D resistivity model in $\mathrm{Z}$ direction at different depths. The black circles are the position of craters. The purple square showed the connection site of the two conduits.
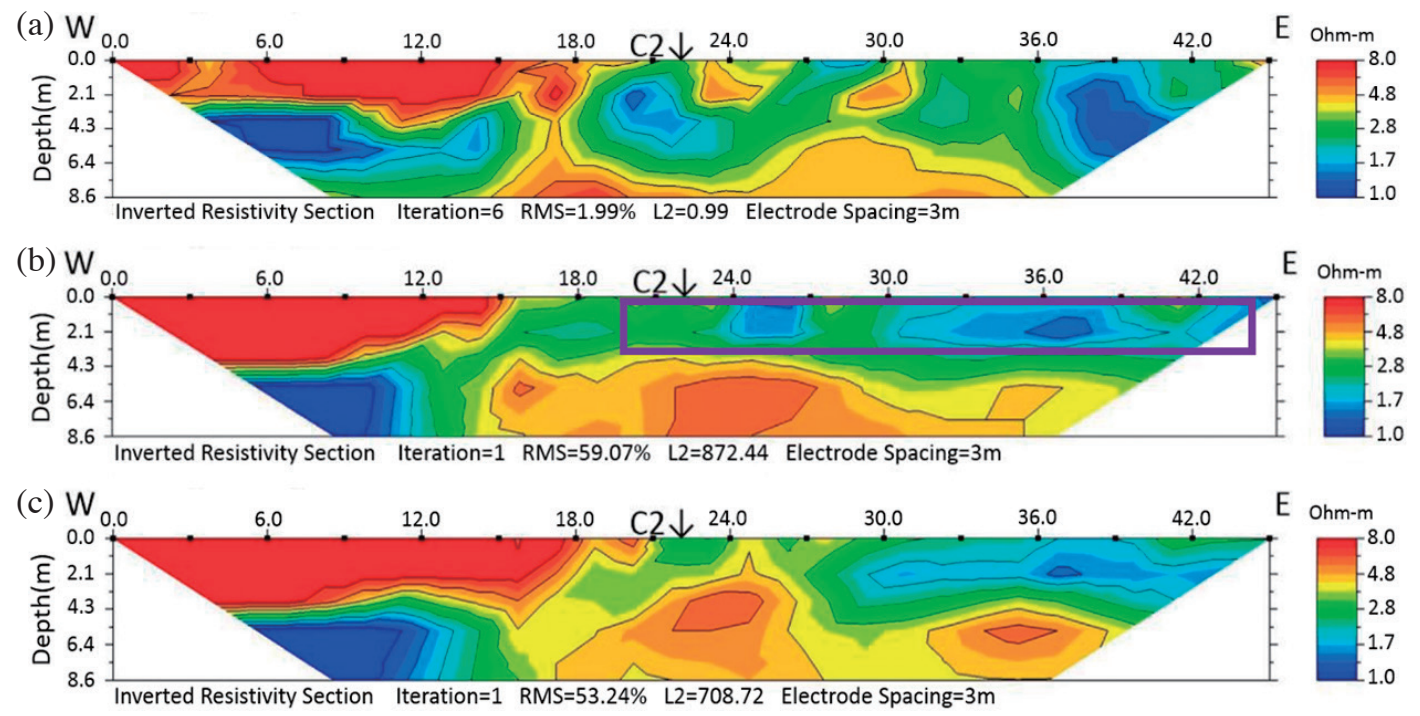

Fig. 7.2D profile section of Line 175 (a), 173 (b), and 171 (c) from west to east, and C2 shows the crater 2. In this section, we can find the horizontal conduit (Purple Square) towards the east of $\mathrm{C} 2$, and in the west, the low resistivity area is located at deeper layer. 

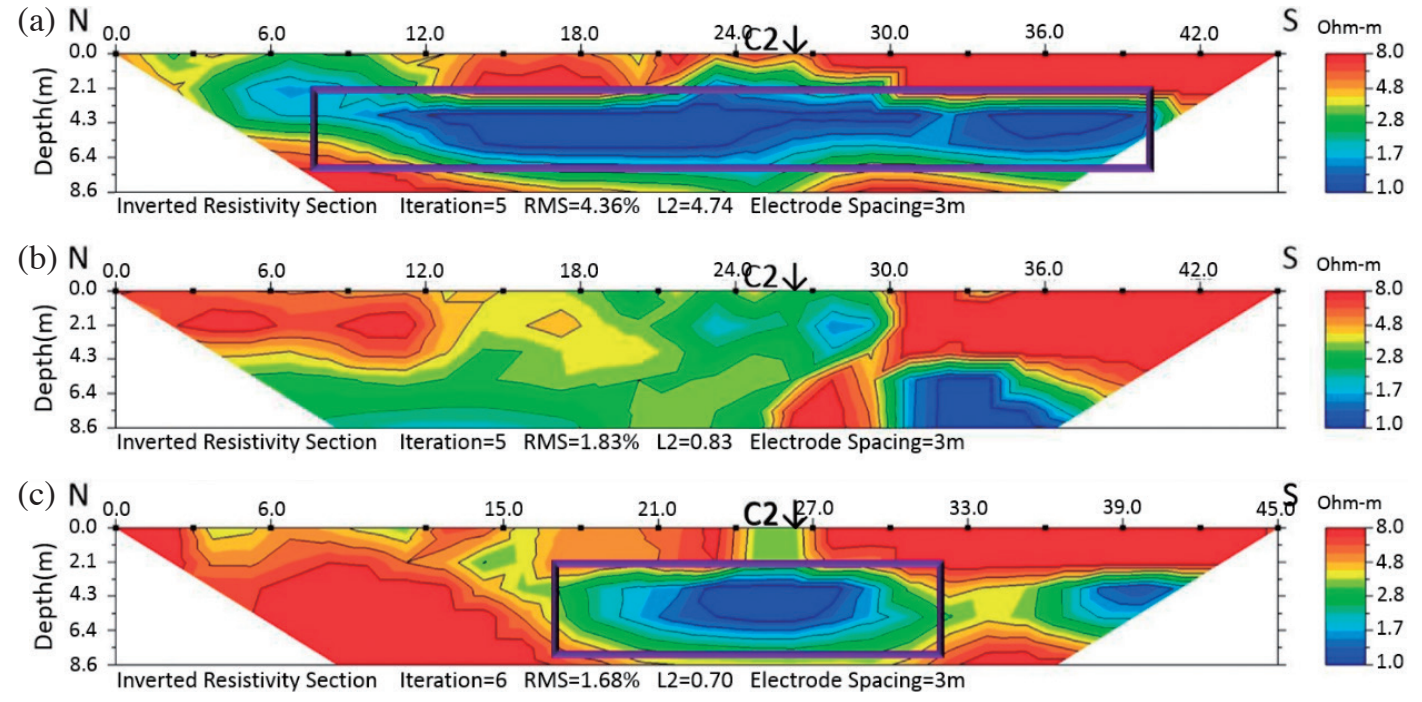

Fig. 8. 2D profile section of Line 179 (a), 177 (b), and 181 (c) in the north-south direction. (a) shows the low resistivity area, distributed along the whole survey line (purple square), and it means that when the conduit passes through the $\mathrm{C} 2$, it becomes horizontal and spreads to north-south; (c) shows the low resistivity was focused beneath the $\mathrm{C} 2$ (purple square), and it mean that the conduit was focused in west below $\mathrm{C} 2$ and was vertical structure.

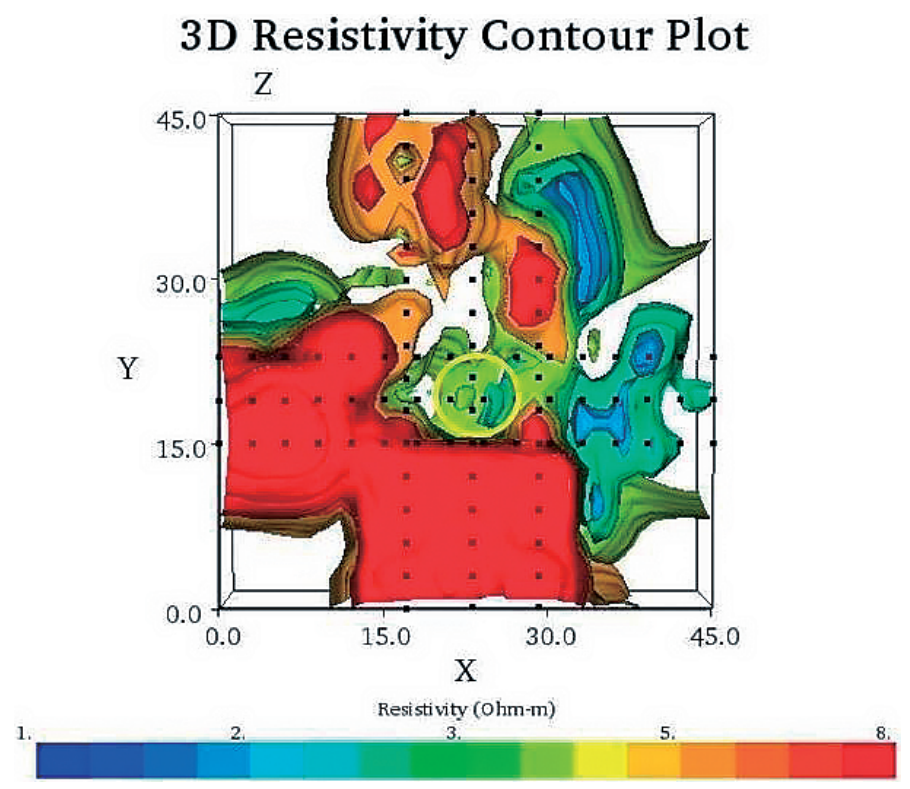

Fig. 9. The 3D model made by combining and inverting the resistivity data along the lines $171,173,175,177,179$, and 181 . The black circle indicates the location of $\mathrm{C} 2$. It is observed that the crater $\mathrm{C} 2$ was surrounded by high resistivity. 

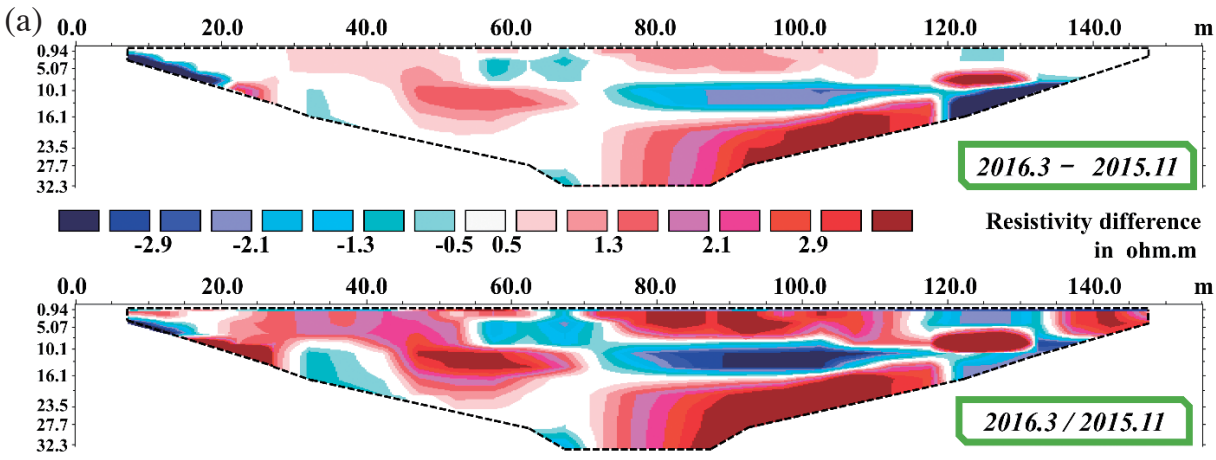

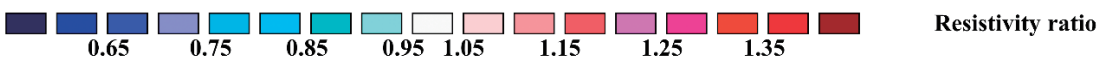
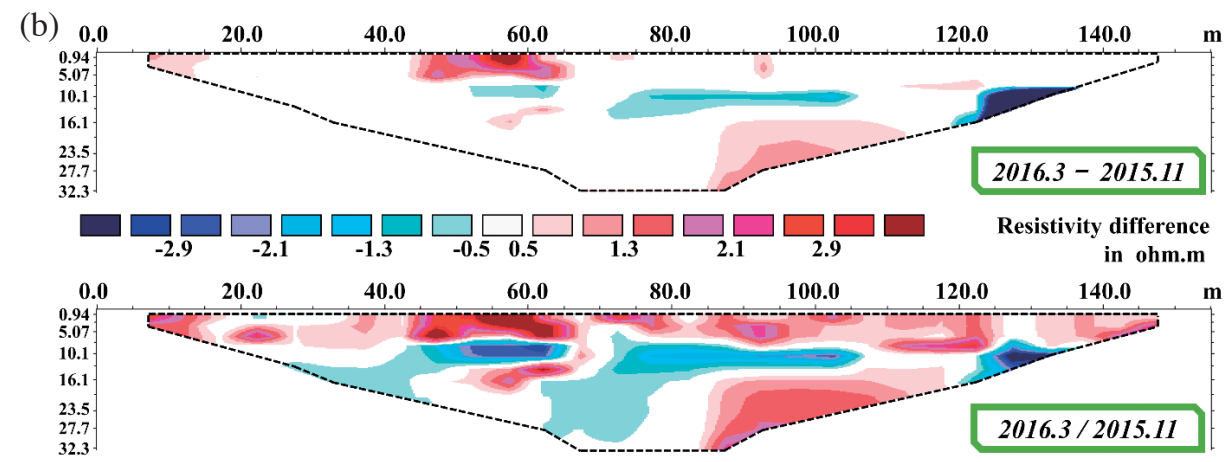

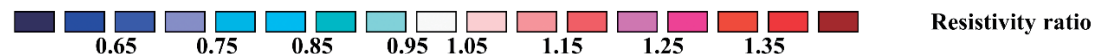

(c)
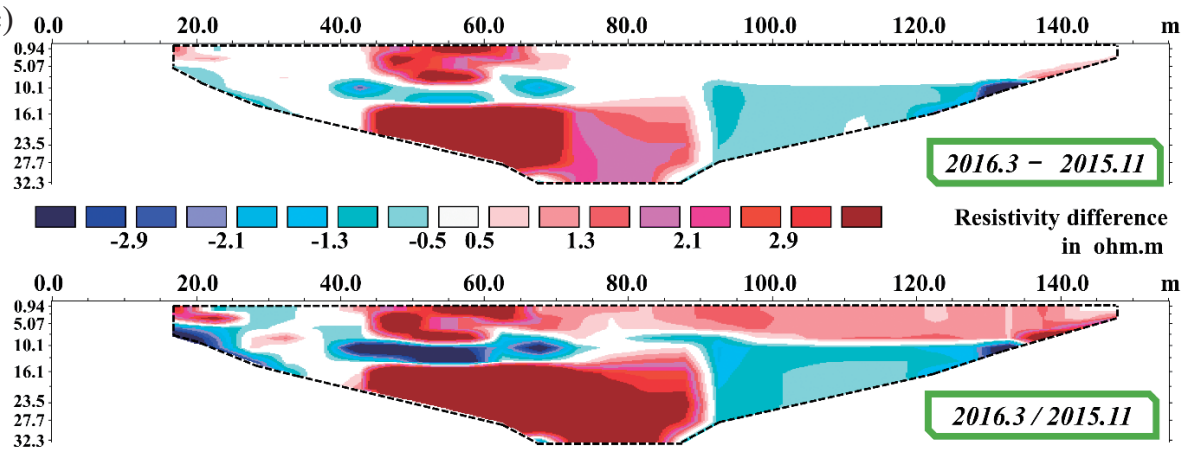

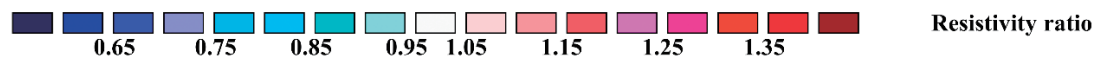

Fig. 10. Resistivity change along three long survey lines 183 (a), 193 (b), and 199 (c) before and after Meinong earthquake of 6 February 2016. 
(a)

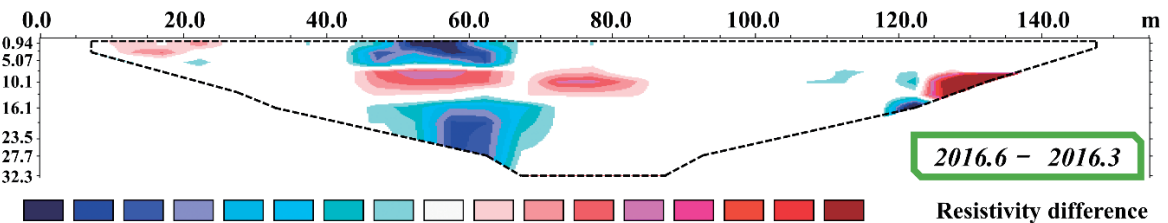

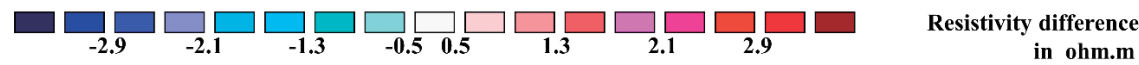

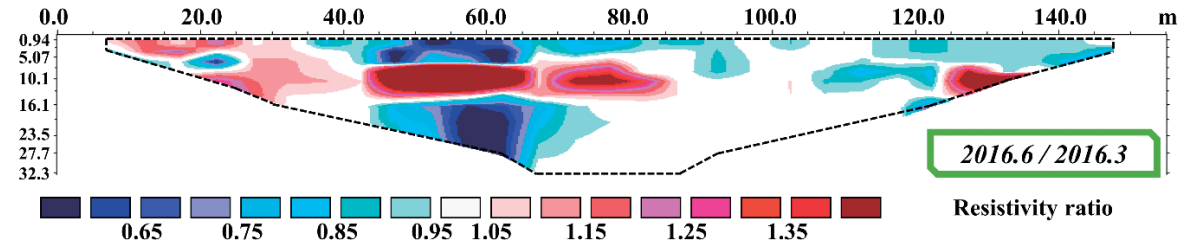

(b) 0.0

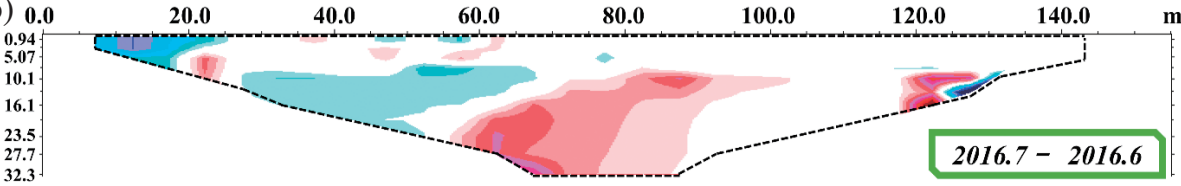

$\square \square \square \square \square \square \square \square \square \square \square \square \square \square \square \square \square \square \square \square$ Resistivity difference

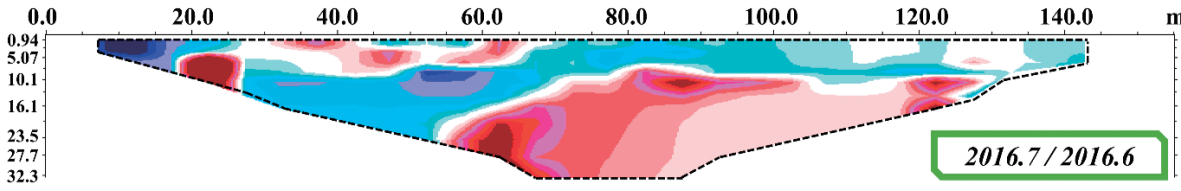

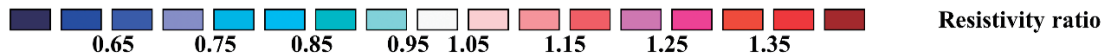

(c)

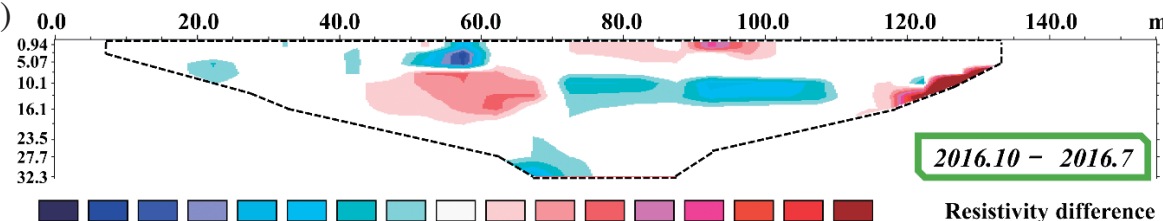

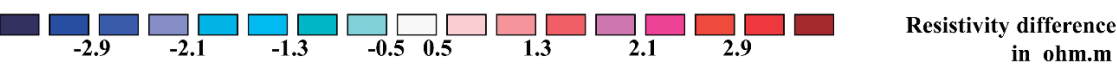

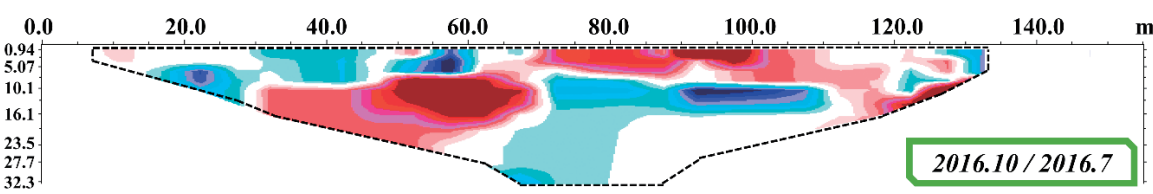

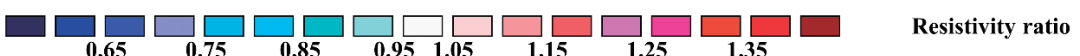
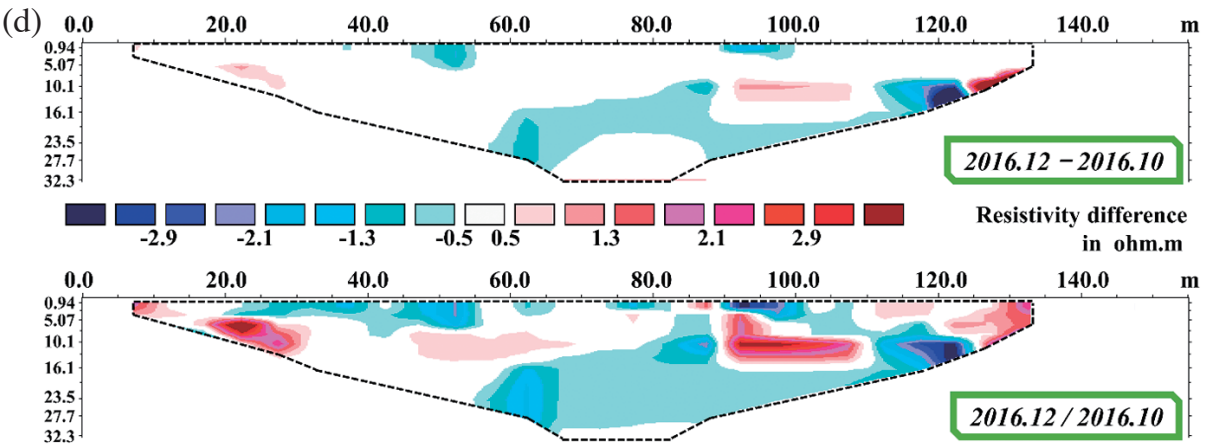

$\begin{array}{llllllllll}0.65 & 0_{0.75} & 0.85 & 0.95 & 1.05 & 1.15 & 1.25 & 1.35 & & \text { Resistivity ratio }\end{array}$

Fig. 11. Resistivity successive change of line 193. 

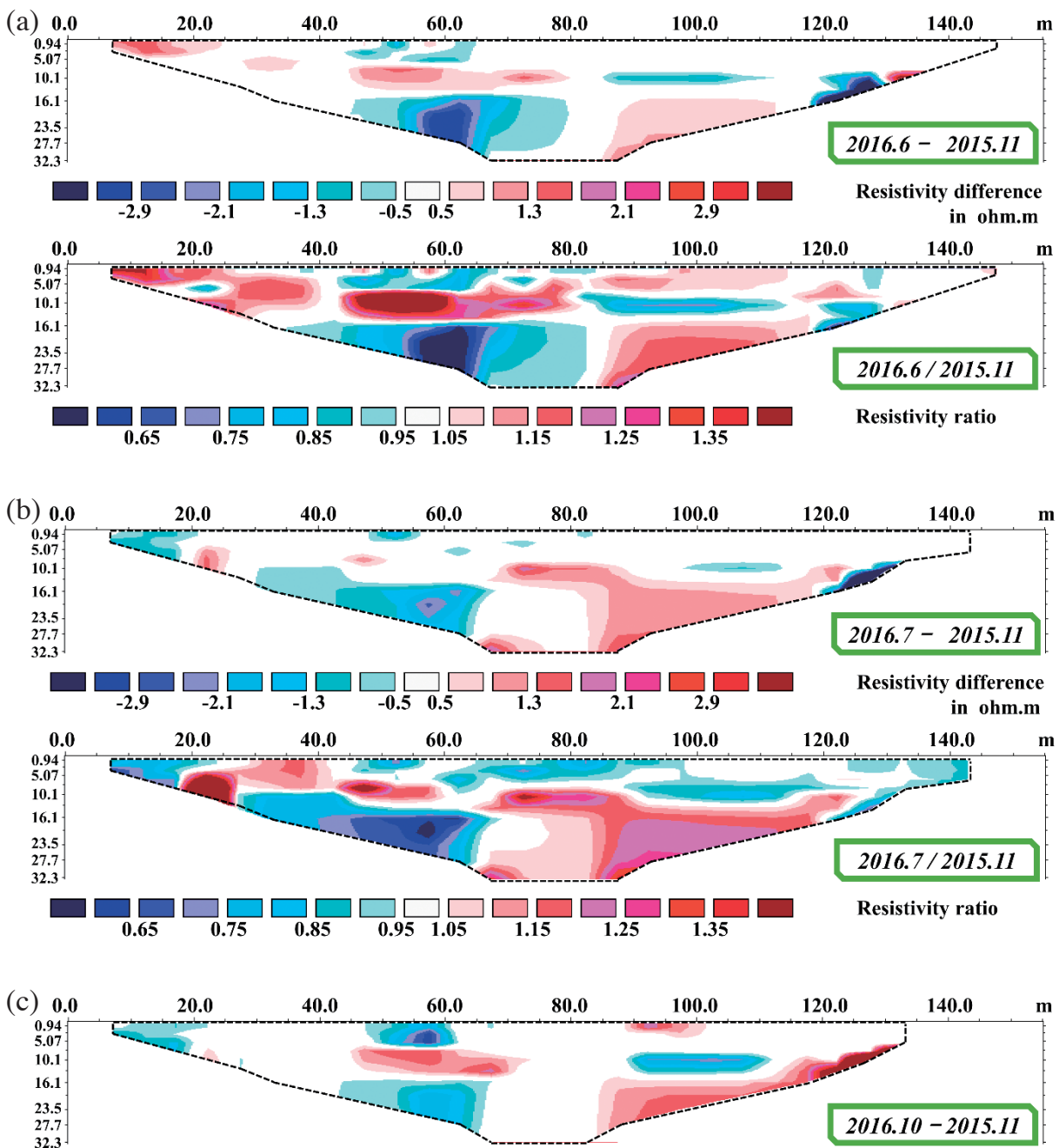

$\square \square \square \square \square \square \square \square \square \square \square \square \square \square \square \square \square \square \square$ Resistivity difference
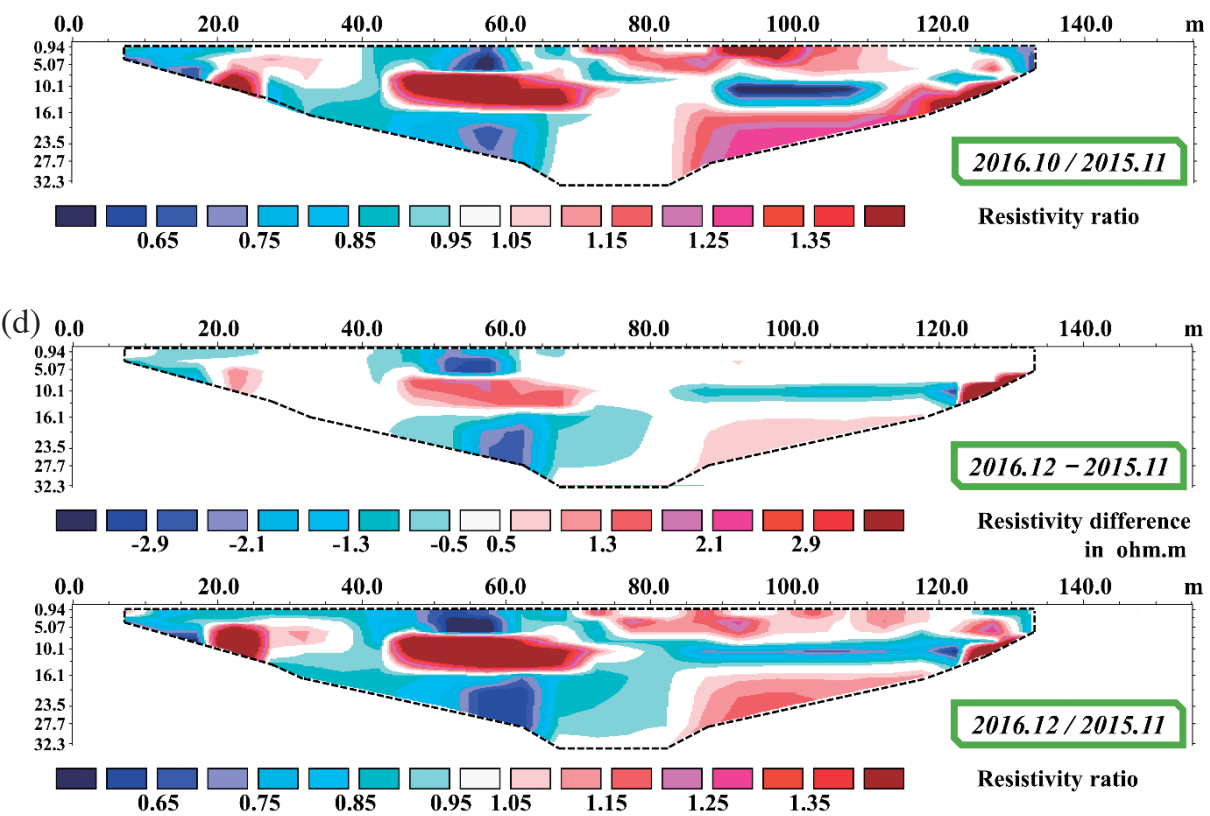

Fig. 12. Comparison of each survey data with pre-earthquake data of line 193. 
selected by the mud volcano system is formed. At the same time, we also observed that there was a recess formed by the accumulation of fluid after a short stop at $10-15 \mathrm{~m}$ below the $\mathrm{C} 4$. The last result shows that in December the resistivity of the bushes was still lower than the initial value. We speculate that there was sporadic rainfall before the survey, and the resistivity of the mud beneath was higher than the initial value expect within $5 \mathrm{~m}$ above the surface. This might be related to the gas accumulation caused by the eruption activity change that has not fully recovered yet.

\subsection{Relationship Between Resistivity and Volume of Water Content}

In order to know the water content distribution in the stratum, we followed the experiment manual of water content in the field of civil engineering to continue our study (measure the water content of soil sample). In order to establish the relationship between the volume of water content and the resistivity, regression is performed. Figure 13 shows two regression lines. The solid line depicts the relationship by using the resistivity data having values less than $500 \mathrm{ohm}-\mathrm{m}$; while the dotted line shows regressed line using whole resistivity data. The estimated regression relationships using both kinds of datasets are shown in Fig. 13. Finally, we use the regression formulae obtained using resistivity values below $500 \mathrm{ohm}-\mathrm{m}$ to plot the water content images according to below function:

$$
\begin{aligned}
& -\log _{10}(\mathrm{ohm}) \\
& =-2.99 \log _{10}(\omega)-0.186-\log _{10}(\mathrm{ohm}) \\
& =-2.99 \log _{10}(\omega)-0.186
\end{aligned}
$$

Using Eq. (1) the resistivity is transformed into the water content and $\mathrm{Z}$ direction cross-section are plotted (Fig. 14). A close relationship is observed between resistivity (Fig. 6) and volume water content (Fig. 14). The areas having a resistivity less than $2 \mathrm{ohm}-\mathrm{m}$ and above $7 \mathrm{ohm}-\mathrm{m}$ (Fig. 6), are found to have volume water content over 0.6 and less than 0.5 (Fig. 14), respectively. The vertical structure beneath the crater C3 is clearly visible (Fig. 14, the high volume water content areas distribute all the sections). The conduit (purple square) which connected the vertical and horizontal conduits was beneath the crater $\mathrm{C} 2$ about $5-12 \mathrm{~m}$.

From the above discussion and comparisons, one can see that mud volcano belongs to a system that is sensitive to the external factors. Overall, the earthquake mainly affects the whole system of mud volcanoes directly by changing the crater position and the mud resistivity. Based on the results obtained by surveying along three lines, the almost consistent increase in resistivity within $10 \mathrm{~m}$ below the surface can be found after the Meinong earthquake. Previous studies have found that the gas emitted here contains about $95 \%$ of methane (Chao and You 2003; Yeh 2003; Yang et al. 2002), whose weight is lighter than the atmosphere; so the result of accumulation appears to the surface, and then evolves over time gradually from the surface to the atmosphere, bringing back to the pre-earthquake state. But the original craters of the fissure may not have been able to recover due to the earthquake so that those were in a state of deactivation until the end of the study period.

\section{CONCLUSION}

In Gunshuiping mud volcano system, the main mudfluid erupting conduit was found beneath the crater $\mathrm{C} 3$. In addition, at a depth about $3-14 \mathrm{~m}$, there was a mud-fluid chamber (Fig. 4b), purple square), whom we interpret to be temporary storage during the mud-fluid eruption.

A conduit parallel to West-East direction near the surface is found below craters $\mathrm{C} 2$ and $\mathrm{C} 1$, connecting the two craters. Beneath the $\mathrm{C} 2$ and $\mathrm{C} 3$, the vertical structure had a branch toward the east and is found to connect with the parallel conduit between $\mathrm{C} 2$ and $\mathrm{C} 1$ at a depth about $5-12 \mathrm{~m}$. This phenomenon showed the three craters are in communicating stage with each other.

During the study period, the mud volcano went through the large-scale earthquake and typhoons. We observed that both of them have a certain degree of impacts on mud volcano activities. When the earthquake occurs, the mud is affected by seismic waves, just like shaking the soda, the gas is hard to be saved in the mud so that it escapes to the surroundings and causes the gas content of the shallow surface to increase. The gas content of the mud decreases at the same time. Moreover, as evolving over time, the mud volcano system affected by the earthquake will gradually recover by itself. Taking the example of Meinong earthquake during the study period; the Meinong earthquake happened on 6 February 2016, and mud volcano system regained its original position about five to six months later of the earthquake. We also found that after the Meinong earthquake, the original active crater (C3) had stopped and was replaced by another crater $(\mathrm{C} 1)$ in the area. Besides, as the cracks of the original crater collapsed, the gas needed another crack to release; so that made another crater re-activate. In addition to the earthquake, we also observed that rainfall plays an important role in mud volcanic activity. The obtained data also shows that there was a decrease of resistivity in most areas when there was significant rainfall before the measurement. On the contrary, the resistivity of mud in the dry season is found to increase slightly due to the decrease in water content. However, after the typhoon, a different situation in contrary to the aforesaid was observed. We found that the crater $(\mathrm{C} 1)$ created after Meinong earthquake had stopped again and a new crater $(\mathrm{C} 4)$ within $20 \mathrm{~m}$ of $\mathrm{C} 1 \mathrm{had}$ activated to continue the activity, we suggested that this result shows the recovery mechanism of mud volcano after 


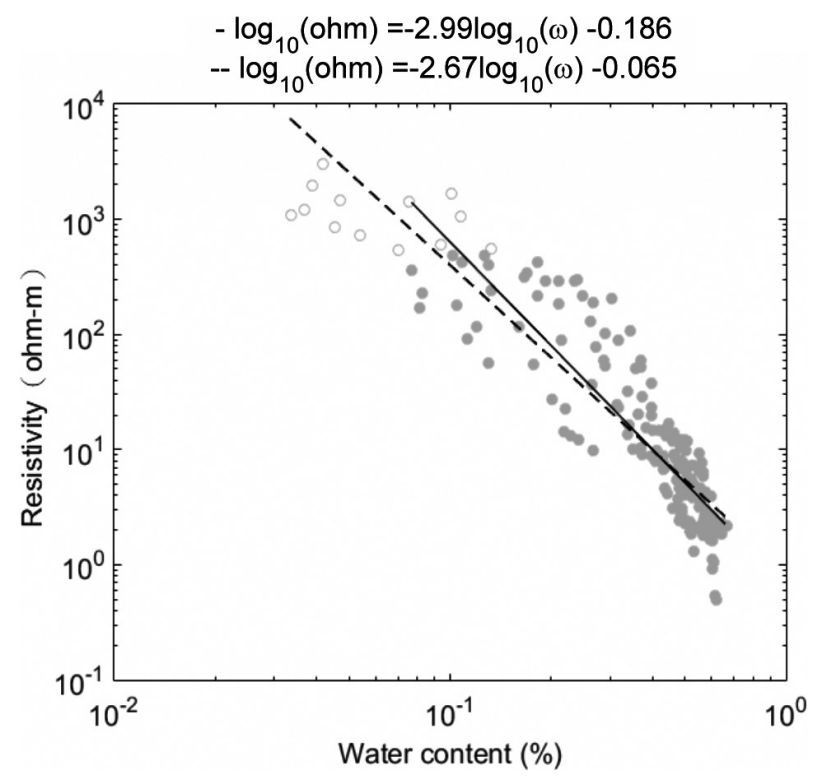

Fig. 13. The relationship between the resistivity and the volume of water content. The solid line is the regression line using resistivity data below $500 \mathrm{ohm}-\mathrm{m}$, and the dotted line is regression using whole data.
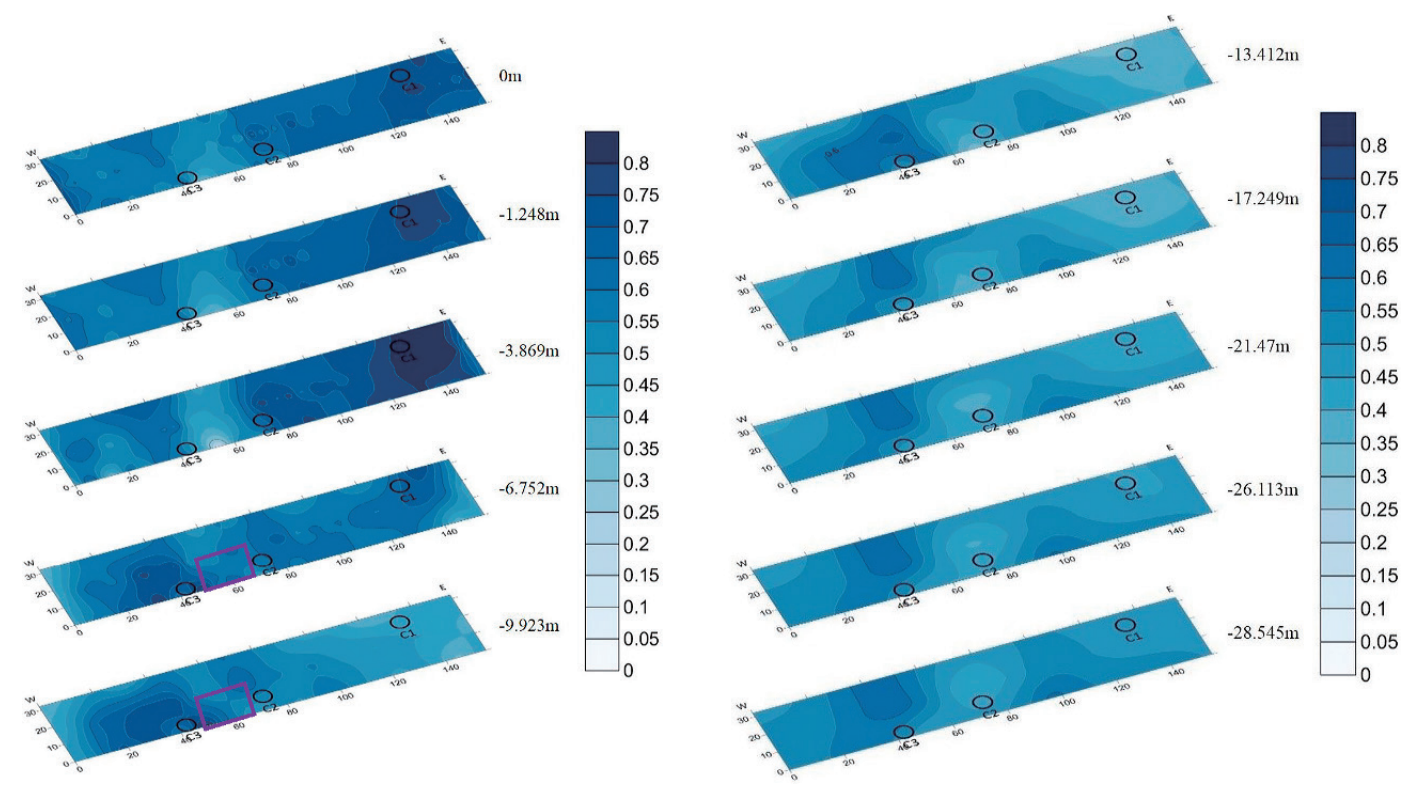

Fig. 14. The cross sections of 3D volume water content in $\mathrm{Z}$ direction at different depths same as that of resistivity in Fig. 6 . We can find that when resistivity is less than $2 \mathrm{ohm}-\mathrm{m}$ and over $7 \mathrm{ohm}-\mathrm{m}$ (Fig. 6), their volume water content is over 0.6 and less than 0.5 , respectively. The purple square shows the location of connecting. 
the crack collapse by non-earthquake caused. The mud volcano still looked for a new crack to keep the activity going, but this time the gas is not be affected, so it accumulated in mud-fluid continually that the resistivity rose.

A close relationship is observed between resistivity and volume of water content. The areas having a resistivity less than $2 \mathrm{ohm}-\mathrm{m}$ and above $7 \mathrm{ohm}-\mathrm{m}$, are found to have volume water content over 0.6 and less than 0.5 , respectively.

Acknowledgements This work was performed under a project sponsored by Ministry of Science and Technology, Taiwan (Grant number MOST 106-2116-M-006-003). The authors are extremely thankful to two anonymous reviewers and Tada-nori Goto, Executive Guest Editor, whose constructive comments helped in improving the quality of manuscript.

\section{REFERENCES}

Bernstone, C., T. Dahlin, and P. Jonsson, 1997: 3D Visualization of a Resistivity Data Set - An Example From A Sludge Disposal Site. Proceedings of the Symposium on the Application of Geophysics to Engineering and Environmental Problems 1997, Environmental \& Engineering Geophysical Society, Reno, Nevada, $917-$ 925, doi: 10.4133/1.2922473. [Link]

Chang, P.-Y., T.-Y. Yang, L. L. Chyi, and W.-L. Hong, 2010: Electrical Resistivity Variations Before and After the Pingtung Earthquake in the Wushanting Mud Volcano Area in Southwestern Taiwan. J. Environ. Eng. Geophys., 15, 219-231, doi: 10.2113/JEEG15.4.219. [Link]

Chang, P.-Y., S.-K. Chang, H.-C. Liu, and S. C. Wang, 2011: Using integrated 2D and 3D resistivity imaging methods for illustrating the mud-fluid conduits of the Wushanting mud volcanoes in southwestern Taiwan. Terr. Atmos. Ocean. Sci., 22, 1-14, doi: 10.3319/ TAO.2010.06.21.01(TT). [Link]

Chao, H. C. and C. F. You, 2003: Chemical Compositions of the Mud Volcano Gases on land in Taiwan: Possible Impact on Global Methane Sources. Master Thesis, Department of Earth Sciences, National Cheng Kung University, Tainan City, Taiwan, 81 pp. (in Chinese)

Chitea, F., 2016: Electrical Signatures of Mud Volcanoes - Case Studies From Romania. 16th International Multidisciplinary Scientific GeoConference SGEM 2016, SGEM2016 Conference Proceedings, Book 1, Vol. 3, 467-474, doi: 10.5593/SGEM2016/B13/S05.059. [Link]

Crawford, M. M., 2018: Hydrologic monitoring and 2-D electrical resistivity imaging for joint geophysical and geotechnical characterization of shallow colluvial landslides. Thesis and Dissertations--Earth and Environmental Sciences, 61, doi: 10.13023/etd.2018.393. [Link]
Dahlin, T. and M. H. Loke, 1997: Quasi-3D resistivity imaging - mapping of three dimensional structures using two dimensional DC resistivity techniques. Conference Proceedings, 3rd EEGS Meeting, cp-95-00037, European Association of Geoscientists \& Engineers, Aarhus, Denmark, 143-146, doi: 10.3997/22144609.201407298. [Link]

Dahlin, T., C. Bernstone, and M. H. Loke, 2002: A 3-D resistivity investigation of a contaminated site at Lernacken, Sweden. Geophysics, 67, 1692-1700, doi: 10.1190/1.1527070. [Link]

Fertl, W. H. and D. J. Timko, 1970: Occurrence and significance of abnormal-pressure formations. Oil Gas J., 5, $97-108$

Hedberg, H. D., 1980: Methane Generation and Petroleum Migration. SG 10: Problems of Petroleum Migration, 179-206.

Higgins, G. E. and J. B. Saunders, 1974: Mud VolcanoesTheir Nature and Origin, Contribution to the Geology and Paleobiology of the Carribean Adjacent Areas. Verhand. der Natur. Geschechaft zu Bazel, 84, 121-152.

Huang, Y. L., L. S. Teng, C. S. Liu, N. Lundberg, and D. L. Reed, 1992: Structural styles of offshore southwestern Taiwan. Eos, Trans., AGU, 73, 539.

Irawan, S. D., P. Sumintadireja, and A. Saepuloh, 2013: 2-D Subsurface ImagingTechniques for Deep Ore Mineral Mapping using Geoelectrical and Induced Polarization (IP) Methods. Procedia Earth and Planetary Science, 6 , 139-144, doi: 10.1016/j.proeps.2013.01.019. [Link]

Liu, C.-S., I. L. Huang, and L. S. Teng, 1997: Structural features off southwestern Taiwan. Mar. Geol., 137, 305319, doi: 10.1016/S0025-3227(96)00093-X. [Link]

Loke, M. H. and R. D. Barker, 1996: Rapid least-squares inversion of apparent resistivity pseudosections by a quasi-Newton method. Geophys. Prospect., 44, 131152, doi: 10.1111/j.1365-2478.1996.tb00142.x. [Link]

Loke, M. H., J. E. Chambers, D. F. Rucker, O. Kuras, and P. B. Wilkinson, 2013: Recent developments in the direct-current geoelectrical imaging method. $J$. Appl. Geophys., 95, 135-156, doi: 10.1016/j.jappgeo.2013.02.017. [Link]

Martinotti, G., M. Lupi, L. Carlucci, E. Cinosi, R. Santacroce, T. Acciavatti, E. Chillemi, L. Bonifaci, L. Janiri, and M. Di Giannantonio, 2015: Novel psychoactive substances: Use and knowledge among adolescents and young adults in urban and rural areas. Hum. Psychopharmacol. Clin. Exp., 30, 295-301, doi: 10.1002/ hup.2486. [Link]

Milkov, A. V., 2000: Worldwide distribution of submarine mud volcanoes and associated gas hydrates. Mar. Geol., 167, 29-42, doi: 10.1016/S0025-3227(00)00022-0. [Link]

Salamov, A. M., S. G. Mammadov, A. H. Gadirov, and R. T. Safarov, 2017: High-resolution vertical electrical 
sounding survey: investigation of subsurface structures at Dashgil's mud volcano, Azerbaijan. International Journal of Development Research, 7, 16688-16692.

Shih, T.-T., 1967: A survey of the active mud volcanoes in Taiwan and a study of their types and the character of the mud. Petrol. Geol. Taiwan, 5, 259-311.

Stride, A. H., R. H. Belderson, and N. H. Kenyon, 1982: Structural grain, mud volcanoes and other features on the Barbados Ridge Complex revealed by Gloria longrange side-scan sonar. Mar. Geol., 49, 187-196, doi: 10.1016/0025-3227(82)90036-6. [Link]

Sugisaki, R. and T. Sugiura, 1986: Gas anomalies at three mineral springs and a fumarole before an inland earthquake, central Japan. J. Geophys. Res., 91, 1229612304, doi: 10.1029/jb091ib12p12296. [Link]

Vignesh, A., N. Ramanujam, P. Prasad, S. H. K. Murti, Q. A. Rasool, S. K. Biswas, C. Ojha, and J. Boobalan, 2013: Characterization of the relationship between the resistivity and gas hydrate concentration in the subsurface of mud volcanoes in Baratang island, Andaman through electromagnetic (Terra tem) Technique. Adv. Appl. Sci. Res., 4, 392-399.
Walia, V., T. F. Yang, S.-J. Lin, A. Kumar, C.-C. Fu, J.M. Chiu, H.-H. Chang, K.-L. Wen, and C.-H. Chen, 2013: Temporal variation of soil gas compositions for earthquake surveillance in Taiwan. Radiat. Meas., 50, 154-159, doi: 10.1016/j.radmeas.2012.11.007. [Link]

Wang, S. H., L. Mei, and C. F. Yang, 1988: Mud volcanoes of Taiwan. Ann. J. Taiwan Museum, 31, 31-49.

Wu, Y.-M., W.-T. Liang, H. Mittal, W.-A. Chao, C.-H. Lin, B.-S. Huang, and C.-M. Lin, 2016: Performance of a low-cost earthquake early warning system $(P$ Alert) during the $2016 M_{\mathrm{L}} 6.4$ Meinong (Taiwan) earthquake. Seismol. Res. Lett., 87, 1050-1059, doi: 10.1785/0220160058. [Link]

Yang, C.-H., P.-H. Cheng, J.-I. You, and L. L. Tsai, 2002: Significant resistivity changes in the fault zone associated with the 1999 Chi-Chi earthquake, west-central Taiwan. Tectonophysics, 350, 299-313, doi: 10.1016/ s0040-1951(02)00146-4. [Link]

Yeh, G.-H., 2003: Geochemistry and Sources of MudVolcano Fluids in Taiwan. Master Thesis, Institute of Oceanography, National Taiwan University, Taipei City, Taiwan, 61 pp. (in Chinese) 